17. Apisarnthanarak A, Mundy LM. The impact of primary prophylaxis for cryptococcosis on fluconazole resistance in Candida species. J Acquir Immun Defic Syndr 2008:47(5):644-645.

18. John L, Nelson M. Primary prophylaxis for cryptococcal meningitis. HIV Med 2004;5(3):131-132.

19. Scharfstein JA, Paltiel AD, Freedberg KA. The cost-effectiveness of fluconazole prophylaxis agains primary systemic fungal infections in AIDS patients. Med Decis Making 1997;17(4):373-381.

20. Yazdanpanah Y, Goldie SJ, Paltiel AD, et al. Prevention of human immunodeficiency virus-relate opportunistic infections in France: a cost-effectiveness analysis. Clin Infect Dis 2003;36(1):86-96.

21. Freedberg KA, Scharfstein JA, Seage GR, 3rd, et al. The cost-effectiveness of preventing AIDS-related opportunistic infections. JAMA 1998;279(2):130-136.

22. Jarvis JN, Lawn SD, Vogt M, Bangani N, Wood R, Harrison TS. Screening for cryptococcal antigenemia in patients accessing an antiretroviral treatment program in South Africa. Clin Infect Dis 2009;48(7):856-862

23. Jarvis JN, Meintjes G, Wood R, Harrison TS. Testing but not treating: missed opportunities and lost lives in the South African antiretroviral therapy programme. AIDS 2010;24(8):1233-1235.

24. Lawn SD, Myer L, Orrell C, Bekker LG, Wood R. Early mortality among adults accessing community-based antiretrovial service in South Africa: implications for programe accessing 2005:19(18):2141-2148.

25. Fairall LR, Bachmann MO, Louwagie GM, et al. Effectiveness of antiretroviral treatment in a South African program: a cohort study. Arch Intern Med 2008;168(1):86-93.
26. Ingle SM, May M, Uebel $\mathrm{K}$, et al. Outcomes in patients waiting for antiretroviral treatment in the Free State Province, South Africa: prospective linkage study. AIDS 2010;24(17):2717-2725.

27. Longley N, Muzoora C, Taseera K, et al. Dose response effect of high-dose fluconazole for HIVLos A, Lorlobry 0 , Micol R, Thahmady A, Lortholary O, et al. Cost-eftectivess of prin associated cryptococcosis in Cambodia. PLos ONe 2010,5(11):e13856.

29. Harling G, Orrell C, Wood R. Healthcare utilization of patients accessing an African national treatment program. BMC Health Serv Res 2007;7:80

30. Haile B, Maartens G, Wood R. Economic evaluation of cryptococcal meningitis and inpatient tuberculosis treatment for HIV-infected adults in South Africa. American Public Health Association 129th Annual Meeting, Atlanta, Georgia, 21-25 October 2001(abstract 25431).

31. Meya DB, Manabe YC, Castelnuovo B, et al. Cost-effectiveness of serum cryptococcal antigen screening to prevent deaths among HIV-infected persons with a CD4+ cell count $<$ or $=100$ cells $/$ microL who start HIV therapy in resource-limited settings. Clin Infect Dis 2010;51(4):448-455.

32. Manosuthi W, Athichathanabadi C, Uttayamakul S, Phoorisri T, Sungkanuparph S. Plasma nevirapine levels, adverse events and efficacy of antiretroviral therapy among HIV-infected patients concurrently receiving nevirapine-based antiretroviral therapy and fluconazole. BMC Infect Dis 2007;7:14.

33. Wakeham $K$, Parkes-Ratanshi $R$, Watson $V$ Ggayi $A B$, Khoo $S$, Lalloo DG Co-administration of Wakeham K, Parkes-Ratanshi R, Watson V, Ggayi AB, Khoo S, Lalloo DG. Co-administration of 2010;65(2):316-319

\title{
MEDICINE AND THE LAW \\ The amended legislation on procedure-related deaths - an advance in patient care?
}

\author{
T E Madiba, Poonitha Naidoo, S R Naidoo
}

Deaths during or after a surgical procedure may be considered medico-legal and subjected to medico-legal autopsy and inquest. We define death in medical terms and discuss the implications of the provisions of the Amended Health Professions Act of 1974 and its recent amendment. Problems with the old and new definitions of such deaths and whether the amendment provides additional patient protection for the patient are considered. We challenge the South African law-makers to review the all-inclusive terminology in relation to such deaths.

\section{Introduction}

Patients who undergo anaesthesia and medical procedures may die as a result thereof. South African law ${ }^{1}$ requires any death considered unnatural $^{2}$ to be reported for medico-legal investigation. Unnatural death related to anaesthesia is provided for in the Health Professions Act. ${ }^{3}$ In July 2008, a revised version of this statutory obligation came into effect with the proclamation of the Health Professions Amendment Act. ${ }^{4}$ We examine the scope and significance of this amendment, and consider its implications for health care providers.

\section{Background and definitions}

The repealed law stated that 'the death of a person whilst under the influence of a general anaesthetic or local anaesthetic, or of which the

Professor T E Madiba is Head of the Department of Surgery and Professor S R Naidoo Head of the Department of Forensic Pathology, University of KwaZulu-Natal, Durban. Ms P Naidoo is an Honorary Research Fellow in the Faculty of Law, University of KZN, and co-ordinator of the Medical Rights Advocacy Network. administration of an anaesthetic has been a contributory cause, shall not be deemed to be a death from natural causes as contemplated in the Inquests Act 58 of 1959, or the Births, Marriages and Deaths Registration Act 81 of $1963{ }^{3}{ }^{3}$

The amendment provides that 'the death of a person undergoing, or as a result of a procedure of a therapeutic, diagnostic or palliative nature, or of which any aspect of such a procedure has been a contributory cause, shall not be deemed to be a death from natural causes as contemplated in the Inquests Act 58 of 1959, or the Births and Deaths Registration Act 51 of 1992.'

Legislative protection for the anaesthetised patient appeared shortly after the introduction of anaesthesia to facilitate invasive surgical procedures. ${ }^{5}$ The drug-induced state of deep unconsciousness and loss of voluntary faculties places patients in a position of vulnerability to hazards of the anaesthesia, and also in a totally compromised state where their lives are subject to the conduct of the health practitioners involved. The expectancy of death following procedures performed under anaesthesia varies widely, from 1 in 133 patients in Togo to 1 in 185000 in the UK, raising concern about anaesthesia and perioperative safety in developing countries. ${ }^{6}$ The peri-operative death rate from inpatient surgery in industrialised countries is between $0.4 \%$ and $0.8 \%$, and at least half of all surgical complications may be avoidable. ${ }^{7}$ However, deaths caused by the anaesthetic procedure alone account for fewer deaths compared with the surgical procedure itself, with mortality associated with general anaesthesia alone ranging from $0.02 \%^{8}$ reported in Finland, to $0.06 \%{ }^{9}$ reported as a global figure.

\section{Issues pertinent to South Africa}

The amendment in South African law appears to be related to the requirement for health professionals to recognise the need for greater protection for the vulnerable patient under their authority and care. ${ }^{10}$ The wider-ranging provision in section 48 of the Health Professions Amendment Act permits legal inquiry into deaths which may have evaded investigation under the repealed section 56 of the Health Professions Act. 
Gordon et al. ${ }^{11}$ reported that $94 \%$ of anaesthetists in South Africa admitted to a drug administration error. A small but important number of cases led to morbidity or death, thereby expressing the need for greater awareness and reporting mechanisms to identify and manage risks.

Although anaesthesia accounted for few of the maternal deaths in the First Report on Confidential Enquiries into Maternal Deaths in South Africa, it was an important and preventable cause related to substandard care. Almost $67 \%$ of maternal deaths reported as being related to the anaesthetic were directly caused by the anaesthetic itself, mainly general anaesthesia, citing human error or professional incompetence as a main element of causation; the prevalent event being failed intubation. ${ }^{12}$ Rout decried the lack of autopsy examinations and the poor quality of medical records in this review (of anaesthetic-related maternal deaths), making a strong point about the need to review the term 'anaesthetic death' as it obscures the more substantial and significant cause of such deaths. ${ }^{12}$

Few of these anaesthetic-related maternal deaths were directly linked to the anaesthesia itself, the majority being due to the condition of the patient that necessitated the medical procedure, or a pre-existing co-morbid condition. What is important is that these deaths are eminently preventable. Sadly, all subsequent maternal death reports show a similar trend in the incidence of anaestheticrelated deaths. ${ }^{13}$ In tandem with the fifth Millennium Development Goals, ${ }^{14}$ which ought to be realised by 2015 , maternal health would be greatly advanced by reduction in avoidable maternal deaths associated with anaesthesia. ${ }^{6}$

\section{Discussion}

Legislation as to which deaths that take place under the care of a health professional are reportable for medico-legal investigation differs between countries and even between jurisdictions within some countries. Whether an unnatural death is reported appears to be dependent upon the sophistication of the reporting system, the number of complex surgical procedures managed, and the death investigation system in place. In most countries, deaths that occur within a short time period after a surgical operation or during an invasive procedure, and those that occur under the influence of anaesthesia or to which the administration of an anaesthetic was a contributory cause, become the subject of a medico-legal investigation. ${ }^{15}$

The lack of guidelines for the interpretation of the reporting legislation in South Africa has led to difficulties in applying the law to individual cases. While the original clause in section 56 of the Health Professions Act made deaths related to anaesthesia reportable, there was no specific provision for the reporting of death related to a procedure. Further, reporting was left to the discretion of the practitioner, raising the possibility that some deaths that would otherwise justify medico-legal investigation could be signed off as due to natural causes. Deaths that merit investigation on the basis of possible medical error may therefore be overlooked. The question that must be considered is whether death would have occurred if the medical intervention had not taken place. ${ }^{15}$ However, although the law is now amended, the clinician in charge is still responsible for reporting an unnatural death. Additionally, while the repealed legislation generally held the surgeon or anaesthetist as carrying the main burden of liability for a death, the amended rule could have any registered health care professional held so accountable.

Anaesthesia places a person in an unnatural state of unconsciousness that is associated with inherent but preventable risks. In the amendment, all prescripts relating to anaesthesia are now excluded and replaced by one relating to 'procedure'. While attempting to broaden the interpretation beyond 'anaesthetic', it involves the perilous possibility of excluding deaths directly related to the anaesthesia. The vulnerability and protection of the anaesthetised patient is therefore not addressed. It is a significant omission to exclude adverse effects relating to the anaesthetic and other drugs and interventions used in anaesthesia. The amended rule does not provide reassurance that the all-inclusive term 'procedure' would suffice to include deaths related to the anaesthetic for purposes of reporting.

In respect of the period of time after general anaesthesia, death was considered reportable if the patient died before recovering consciousness. ${ }^{16}$ In contrast, if death took place even within a few hours of the anaesthetic, but with initial full recovery of consciousness and no causal association with the anaesthetic itself, they would not be regarded as related. However, where an earlier adverse event such as aspiration or airway obstruction may have occurred during anaesthesia, and death occurred due to subsequent related complications in spite of regaining wakefulness, the anaesthetic should be considered contributory. Notwithstanding the duration of time elapsed after the anaesthetic, the death may therefore still be related if a causal association between the anaesthetic and the death can be demonstrated. ${ }^{16}$

International trends show that deaths occurring during or within a short time after either a surgical or invasive procedure or an anaesthetic are generally subjected to medico-legal investigation, notwithstanding the interval between the intervention and death, as long as a plausible causal relationship can be assumed. ${ }^{17}$ This seems a rational approach where there are concerns that previous legislation allowed for an unacceptable failure to investigate those deaths that may have been due to negligence, or those that were patently avoidable. The argument ${ }^{17}$ that the best term for such deaths should be 'anaesthetic and procedure-related deaths' is compelling.

The suggested terms 'peri-operative' and 'postoperative' death ${ }^{17}$ are also vague, and deaths resulting from procedures under anaesthesia but not in an operating room may be excluded from reporting. Surprisingly, South African clinicians often persist in using a '24-hour' rule to decide whether a death following an anaesthetic or surgical procedure is reportable, although no such rule exists in South Africa.

In the early postoperative period where the patient has not recovered from the anaesthetic, many deaths are due to questionable circumstances, and the clinician may be unsure about causation and on reporting. To avoid these possible unnatural deaths being missed, it would be useful if there were a time specification for reporting the death. A time limit of 24 hours would serve this purpose most appropriately, and be in line with global trends and leading international practices. ${ }^{18}$ For such patients the clinician would not then be required to exercise a sometimes fallible discretion, as all the early deaths during this 'grey' area would automatically be reported.

The term 'procedure' is not defined in the amended law. It is not clear whether it is inclusive of any procedure regardless of nature or complexity. Hazards during diagnostic procedures include many deaths from interventional radiology procedures. ${ }^{19}$ Therapeutic procedures can be the surgery itself, whether major or minimally invasive, and could also relate to drug therapy alone: the Institute of Medicine reported that up to 98000 preventable deaths a year caused by adverse drug events occurred in health institutions in the USA. ${ }^{20}$ On the other hand, deaths from palliative procedures may have escaped scrutiny. Palliative medicine aims to ease pain and provide relief from distress; medical error that negligently shortens the life of a patient, even with terminal disease, is a drop in the standard of 
care..$^{21}$ Any medical interference, including research and experimental interventions, may also be regarded as procedures.

To counter the challenge of a possible increase in the number of reportable deaths and the expected burden to the investigative and medico-legal services, the law should provide in reported cases for the state forensic pathologist or inquest magistrate to have the discretion, in consultation with relevant medical specialist experts as required, to consider whether further medico-legal investigation is required. This evaluation could be done in the form of an official consultation with full documentation accompanying the reporting. A full postmortem examination could be done when it is considered necessary to establish the mechanism and cause of death, and/or where liability on the part of any health provider or institution may be at issue.

\section{Recommendations}

The proposal to the Health Professions Council of South Africa is to review the amendment and its terminology. A more precise definition, with broader inclusivity, is needed. It would be prudent for legislators to swiftly review and revise the specific provisions of the recent amendment for best outcome.

To best define health care-related deaths that should be subject to medico-legal investigation, we advocate use of both the terms 'anaesthetic-related' and 'procedure-related', and inclusion of a 24 -hour rule in the wording of the legislation. A more precise wording could be a composite of the following essential components:

'The death of a person whilst undergoing a general, regional or local anaesthetic or a medical or surgical procedure, or of which the administration of an anaesthetic or the undertaking of a procedure has been a contributory cause, shall not be deemed to be a death from natural causes, provided that:

i. All deaths within 24 hours of the administration of anaesthetic or performance of a procedure must be the subject of a medicolegal investigation;

ii. A procedure is defined as any medical or surgical procedure, including but not limited to that of a diagnostic, therapeutic or palliative nature, but which, in the opinion of the attending clinician, was associated with material risk of injury or death; and

iii. The nature and extent of the medico-legal investigation must be left to the discretion of a state pathologist or magistrate of the district in which the death occurred.'

\section{Conclusions}

Health care providers have a crucial obligation in reporting unnatural deaths of patients under their care. Increased use of medical technology, the ability to treat patients who were previously not considered operable, including the requirement that patients undergoing diagnostic and palliative procedures should be equally considered, increases the risk of error, and therefore calls for increased attentiveness by health practitioners.

The amendment is progressive as it allows for a legal inquiry into a death that would not have occurred if the patient had received a reasonable standard of care during the medical intervention. Further, if negligence is confirmed during an inquest, a patient's next of kin may proceed with a civil claim for material damages suffered due to the untimely death of their family member. Vulnerable patients deserve this protection, particularly where service delivery is poor, with fewer resources and little access to optimal health care. Lack of resources should not allow us to drop our vigilance towards patient protection.

The Inquests Act 58 of 1959 and The Births and Deaths Registration Act 51 of 1992

Section 1 of the Regulations regarding the rendering of Forensic Pathology Service No. R. 63620 July 2007 of the National Health Act 61 of 2003.

Section 56 of the Health Professions Act 56 of 1974, hereafter the Health Professions Act.

Section 48 of the Health Professions Amendment Act 29 of 2007, hereafter the Health Professions Amendment Act.

5. Ramsay MAE. John Snow, MD: Anaesthetist to the Queen of England and Pioneer Epidemiologist. Proceedings of the Baylor University Medical Center 2006;19(1):24-28.

Walker IA, Wilson IH. Anaesthesia in developing countries - a risk for patients. Lancet 2008:371:968969.

. Haynes AB Weiser TG, William WR et al. A surgical safety checklist to reduce morbidity and mortilty in a global population. N Engl J Med 2009;360(5):491-499.

in a global population. N Engl Med 2009;360(5):491-499.

9. Aitkenhead AR. Injuries associated with anaesthesia. A global perspective. Br J Anaesth 2005;95(1):95109.

0. Section 3 (j) of the Health Professions Amendment Act.

1. Gordon PC, Llewellyn RL, James MFM. Drug administration errors in South African anaesthetists - a survey. S Afr Med J 2006;96(7):630-632.

2. Rout C. Anaesthetic-related deaths. In: Pattinson R, ed. Saving Mothers. Report on Confidential Enquiries into Maternal Deaths in South Africa. Chapter 7. 1998. http://www.doh.gov.za/docs/reports/ mothers/contents.html (accessed 25 September 2010).

13. National Committee on Confidential Enquiries into Maternal Deaths. Saving Mothers 2005-2007: Fourth Report on Confidential Enquiries into Maternal Deaths in South Africa. Expanded Executive Summary. Pretoria: Department of Health, 2007: 12. http://www.doh.gov.za/docs/reports/2007/ savingmothers.pdf (accessed 21 August 2010).

14. United Nations Development Programme. South Africa Millennium Development Goals Country Report. 2005: 28-33. http://www.doh.gov.za/docs/reports/2005/mdgd/part3.pdf (accessed 15 August 2010).

15. Knight B. Deaths associated with surgical procedures. In: Knight B, ed. Forensic Pathology. 2nd ed. London: Arnold, 1996: 475-481.

6. Schwar TG, Loubser JD, Olivier JA. The Forensic ABC in Medical Practice. Pretoria: Haum, 1988: 265. 7. Start RD, Cross SS. ACP. Best Practice No. 155. Pathological investigation of deaths following surgery, anaesthesia, and medical procedures. J Clin Pathol 1999;52(9):640-652.

8. New South Wales Legislation, Australia. Section 6(g) of the Public Health (General) Regulation 2002.

19. Grocott MPW, Ingram S. Perioperative deaths. In: Payne-James J, Busuttil A, Smock WS, eds. Forens Medicine: Clinical and Pathological Aspects. London: Greenwich Medical Media, 2003: 201-212.

20. Kohn L, Corrigan J, Donaldson M, eds. To err is human: Building a safer health system. Committee on Quality of Health Care in America, Institute of Medicine. Washington, DC: National Academy Press, 2000: 26-28.

1. Kelly AS, Meier DE. Palliative care - a shifting paradigm [Editorial]. N Engl J Med 2010;363(8):781782 